\title{
The effect of early versus late lipid infusion in parenteral nutrition on the biochemical and cortical auditory evoked potential parameters in preterm neonates
}

\author{
Rania Mohamed Abdou ${ }^{1}$ and Hoda Mahmoud Ibrahim Weheiba ${ }^{2 *}$
}

\begin{abstract}
Background: As brain activity depends greatly on the functions provided by lipid membranes, dietary fat in early life can affect the developing nervous system. Despite the adoption of an early more aggressive parenteral nutrition approach with amino acid infusions still reluctance to the early use of intravenous lipids in neonates.

Aim: To compare the effect of delayed versus early introduction of intravenous lipid in preterm on the biochemical parameters and on brain development by the cortical auditory evoked potential (CAEP) latency and amplitude.

Methods: This is a comparative study included 49 neonates admitted the ain shams university NICUs. Participants were divided into two groups: 26 in group of early lipid infusion and 23 in late lipid infusion, Demographic data, and biochemical parameters were documented during the 1 st 2 weeks of life. The CAEP was performed at age of 6 months. The latency and amplitude of P1 were recorded and compared between both groups.

Results: In the present work we found that group of early lipid infusion had reach their full oral intake earlier with shorter duration of parenteral nutrition and length of stay. They had better weight gain and significantly better glucose level control than group of late lipid infusion. There was no significant difference in the other chemical parameters between both groups expect for the higher incidence of cholestasis in the group of late lipid infusion. At 6 months of age, the group of early lipid infusion had significantly shorter latency and amplitude of P1 than the group of late lipid infusion.
\end{abstract}

Conclusion: Early effective nutrition positively affect feeding tolerance and weight gain and maturation of higher brain centers brain.

\section{Introduction}

Nutrition is one of the basic factors for the development of the central nervous system (CNS) and early nutritional deficiency impairs CNS function [1]. Most of the dry weight of the brain is a lipid, roughly $25 \%$ Docosahexaenoic acid (DHA), 25\% stearic acid, 14\% Arachidonic acid (AA), and $12 \%$ oleic acid. During the last trimester and the 1st 12 weeks of life the brain depends mainly on DHA. It is during this period that brain synapses are forming and the

\footnotetext{
* Correspondence: raniaabdou@med.asu.edu.eg

${ }^{2}$ Audiology Department, Unit ENT Departments, Faculty of Medicine, Ain

Shams University, 4, hashem al Ashkar Street, el nozha el gedida, Cairo

11843, Egypt

Full list of author information is available at the end of the article
}

need increases three to five times [2]. As brain activity depends greatly on the functions provided by lipid membranes, dietary fat in early life can affect the developing nervous system [3]. Researchers have noticed that DHA is required for the development of the cerebral cortex and numerous brain functions responsible for signal transmission and cognitive functions. Reduced amounts of DHA causes smaller brain development in early infancy [4]. Many studies recently recommend early more aggressive parenteral nutrition (continuous glucose infusion at a rate of 6$8 \mathrm{mg} / \mathrm{kg} /$ day; protein $3 \mathrm{mg} / \mathrm{kg} /$ day), starting within the first 1-2 $\mathrm{h}$ after birth [5]. But despite the adoption of a more aggressive approach with amino acid infusions still 
reluctance to the early use of intravenous lipids. This practice was based on several dogmas that suggest that lipid infusions may be associated with the development or exacerbation of lung disease, displacement of bilirubin from albumin, thrombocytopenia, and can exacerbation of sepsis [6]. In fact, the data for these are nonexistent, misinterpreted, or lacking and underestimate the effects of malnutrition both reversible and permanent on the central nervous system [7]. There is evidence since the 1950's and 1960's that malnutrition is associated with reduced myelination [8], in the neurophysiological field, changes in electroencephalogram [9] and evoked potentialtracings [10]. Auditory Evoked Potentials (AEP) are very sensitive measures related to brain functions and provide a highly specific representation of auditory-related brain function. Results are highly reproducible among individuals and have been well characterized as a function of stimulus intensity and postnatal age-auditory-related brain [11]. While numerous studies have focused on the anatomical and biochemical changes in the developing brain with malnutrition, few studies have assessed the physiological changes. Taking into account that the most used AEP reaches the level of the brainstem, studies involving higher paths and cortical areas are necessary, focusing on persistence of the effects of malnutrition on higher cortical activity with present and future consequences for development [12]. Our aim was to compare the effect of delayed versus early introduction of intravenous lipid in preterm on the biochemical parameters and on brain development by the cortical auditory evoked potential (CAEP) latency and amplitude.

\section{Methods}

\section{Participants}

This is a comparative study over a period of 12 months from February 2017. Neonates were recruited from ain shams university NICUs and followed up at the neonatology clinic (pediatric department) audiology clinic (ENT department) after approval of the hospital NICU research \& ethical committee and verbal consent from the parents.

Patients were divided into 2 groups according to the time of intravenous lipid infusion introduction to admitted neonates.

- Group of early lipid infusion (ELI): included neonates who received intravenous lipid infusion earlier than $48 \mathrm{~h}$ of life.

- Group of late lipid infusion (LLI): included neonates who received intravenous lipid infusion later that $48 \mathrm{~h}$ of life.

\section{Inclusion criteria}

The study included neonates aged below 32 weeks and weight below $1500 \mathrm{gm}$. Those who received total parenteral nutrition infusion for 1st week of age and not more than
2 weeks before enteral feeding initiation. After discharge infants were prospectively followed up at the neonatology and audiology clinic. The biochemical data of all neonates were studied over 1st 2 weeks of life. They were assessed at the age of 6 months by the CAEP to evaluate their central auditory functions.

\section{Exclusion criteria}

We excluded any patient with comorbidities during NICU admission such as increased mechanical ventilation more than 5 days, secondary neonatal sepsis, necrotizing enterocolitis, patent ductus arteriosus, intraventricular hemorrhage and hypoxic ischemic encephalopathy. To eliminate the confounding effect of other risk factor on the cortical auditory evoked potential results only infants with normal neurological development, normal hearing screening, No history of hearing loss, ear disease, trauma, ototoxic drug intake or ear operation.

The initial sample consisted of 76 preterm during the study period of these 27 (13 in ELI and 14 in LLI group, ) were excluded as they did not match the inclusion criteria: 7 died, 12 received parenteral nutrition below 5 days, 8 had major surgical problems. A total of 49 neonates (26 in ELI and 23 in LLI) were enrolled in the study and continued the full audiological evaluation.

\section{Parenteral nutrition}

Both group started on intravenous dextrose after birth on $80 \mathrm{ml} / \mathrm{kg} /$ day, increased by $10 \mathrm{ml} / \mathrm{kg}$ to reach maximum of $150-200 \mathrm{ml} / \mathrm{kg} /$ day. Glucose started at $6 \mathrm{mg} / \mathrm{kg} / \mathrm{min}$ and increase rate by $1-2 \mathrm{mg} / \mathrm{kg} / \mathrm{min}$ according to glucose monitoring. On day 2 parentral nutrition started with the amino acid (aminoven 10\%, Fersenius Kabi AB, Uppsala, Sweden) starting on $3 \mathrm{gm} / \mathrm{kg} /$ day and reach max of $3.5 \mathrm{gm} / \mathrm{kg}$. In group of late lipid infusion (LLI) prescribing protocol was a daily stepwise increment starting from day 3 at $0.5 \mathrm{gm} / \mathrm{kg} /$ day up to a maximum of $3 \mathrm{gm} / \mathrm{kg} /$ day. In group of early lipid infusion (ELI) we started on day 2 by $1.5 \mathrm{gm} / \mathrm{kg} /$ day with $0.5 \mathrm{gm} / \mathrm{kg} /$ day to reach maximum of $3 \mathrm{gm} / \mathrm{kg} /$ day.

Trophic Feeding of the neonates was starting as early as possible when baby was stable by expressed breast milk and increment of $2 \mathrm{ml} /$ fed every day during 1st week whenever tolerated. Most babies reach full oral by 2 weeks. Started trial of direct breastfed by age of 34 weeks.

\section{Biochemical parameter assessment}

Data included: age, gender, weight of birth and Apgar score

Laboratory (mean values during the 1st week): sodium, potassium, glucose, urea, creatinine, bilirubin, and albumin.

Nutrition parameter: mean weight gain/day during admission, mean days of parenteral nutrition, time to reach full feeds, mean weight gain/month after discharge till 6 months. 


\section{Audiological assessment}

- Full medical and otological history: prenatal, perinatal and postnatal history to exclude any illegible patients with congenital anomalies or history affecting the hearing.

- tological examination (cerumen inspection external ear malformation)

- Patient enrolled in the study passed the 1st stage screening by transient otoacoustic emission. Neonatal hearing screening was conducted at NICU, if newborn didn't meet the pass criteria, test was repeated 1 to 2 weeks later.

- Normal middle ear function by tympanometry by varing pressure from +200 to $-600(\mathrm{daPa})$.

- Equipment:

a) Automated otoacoustic emission (OAE) hand held screening system otodynamic Ltd otopront (stimulus parameters of OAE) done in a quiet room as test is contaminated by noise.

b) Immittancemetery Maico, model MI3

c) Evoked potential response audiometer biologic

\section{Methods}

Each test session included the audiometric testing, electrode application and cortical auditory evoked response recording. Infants were fed and supported by his mother to avoid any interference with the test results.

We inserted earphones and electrodes positioned with electrolytic conductive paste and adhesive tape, after cleaning the skin with abrasive paste. The active (non-inverting) electrode was placed on the vertex $(\mathrm{Cz})$, while the reference (inverting) electrode M1/M2 was placed on the right or left mastoid and the ground electrode was placed on the forehead $(\mathrm{Fz})$. The electrodes were then connected to the preamplifier before passing on to the biologic evoked potential analyzer system, which both analyzed the incoming data as well as generating the auditory stimulus. This stimulus travelled via the amplifier before being presented through inserted receiver. To ensure balanced inputs to the differential amplifier and optimize signal to noise ratio, electrode impedance were kept below 5 Ohms. P1 obligatory cortical auditory responses were recorded in response to tone bursts stimuli at 500 and $2000 \mathrm{~Hz}$, applied. The stimuli were presented at a rate of $0.5 \mathrm{~Hz}$ pulsed / $\mathrm{sec}$ and at a supra-threshold level of $70 \mathrm{~dB}$ in HL.

P1 Obligatory cortical auditory evoked responses were recorded using filter settings of $0.1-50 \mathrm{~Hz}$. The time window was taken as 500 ms. At least two runs of 200 response sweeps were collected for each subject. Amplitude- based artifact rejection level was set between 50 and $90 \mu \mathrm{v}$ for infant test.

P1 morphology was evaluated and waveforms were judged replicable based on visual inspection of the recordings .P1 was defined as the first robust positivity in the waveform in the latency range from 40 to $300 \mathrm{~ms}$ with waveform repeatability. Latency and amplitude values were determined for P1. Amplitude describes the strength of the response in micro volts $(\mu \mathrm{v})$. Latency describes the amount of time, in milliseconds (ms), that it takes to generate the bioelectrical response following stimulus onset.

P1 latency is measured at the center of the peak as the time in msec from stimulus onset to the peak, and P1 amplitude measures were made from baseline to peak [13].

\section{Results}

As regard the demographic data, there were no significant differences in gender percent, birth weight, gestational age or median 5 min Apgar scores (Table 1).

\section{Parenteral nutrition}

In the group of Early lipid infusion mean post-natal age of lipid start was much earlier with shorter duration to reached full lipid infusion and time course of parenteral nutrition ( $2.37 \pm 0.42$ days, $5.5 \pm 0.57$ days, $10.5 \pm 1.73$ days respectively) compared to group of Late lipid infusion (3.75 \pm 0.75 days, $7.67 \pm 0.87$ days, $15.17 \pm 1.7$ days in LLN respectively). This was statistically significant $(p=0)$.

Table 1 Demographic data of the studied population

\begin{tabular}{|c|c|c|c|c|c|c|}
\hline & & \multirow{2}{*}{$\begin{array}{l}\text { Early lipid infusion } \\
\text { No. }=26\end{array}$} & \multirow{2}{*}{$\begin{array}{l}\text { Late lipid infusion } \\
\text { No. }=23\end{array}$} & \multirow{2}{*}{$\begin{array}{l}\text { Test } \\
\text { value }\end{array}$} & \multirow[t]{2}{*}{$P$-value } & \multirow[t]{2}{*}{ Sig. } \\
\hline & & & & & & \\
\hline \multirow[t]{2}{*}{ Gender } & Male & $15(57.7 \%)$ & $10(43.5 \%)$ & $0.987^{*}$ & 0.321 & NS \\
\hline & Female & $11(42.3 \%)$ & $13(56.5 \%)$ & & & \\
\hline \multirow[t]{2}{*}{ BW/kg } & Mean \pm SD & $1.22 \pm 0.11$ & $1.25 \pm 0.13$ & $-0.940^{\circ}$ & 0.352 & NS \\
\hline & Range & $1.03-1.4$ & $1-1.5$ & & & \\
\hline \multirow[t]{2}{*}{ GA(weeks) } & Mean \pm SD & $30.67 \pm 1.24$ & $30.89 \pm 1.26$ & $-0.622^{\circ}$ & 0.537 & NS \\
\hline & Range & $29-32$ & $29-32$ & & & \\
\hline \multirow[t]{2}{*}{ Median apgar at $5 \mathrm{~min}$} & Mean \pm SD & $7.46 \pm 0.71$ & $7.35 \pm 1.11$ & $0.432^{\circ}$ & 0.667 & NS \\
\hline & Range & $6-9$ & $6-9$ & & & \\
\hline
\end{tabular}

*: Chi-square test

$\bullet:$ Independent $t$-test 


\section{Enteral nutrition}

The group of Early lipid infusion had statistically significant $(p=0)$ earlier start of their oral fed and achievement of their full oral intake $(4.46 \pm 1.3$ days and $15.19 \pm$ 2.86 days) than group of Late lipid infusion (5.61 \pm 1.31 days and $19.13 \pm 2.6$ days respectively). Significantly shorter length of stay in NICU in group of Early lipid infusion compared to group of Late lipid infusion (18.96 \pm 5.37 days) versus $(22.61 \pm 5.24$ days $)(p=0.02)$.

\section{Weight gain}

The weight gain /day during the hospital stay and during the 1st 6 month of life was significantly higher in group of Early lipid infusion $(20.85 \pm 4.95 \mathrm{~g}, 771.92 \pm 58.8 \mathrm{~g})$ than that of Late lipid infusion $(15.35 \pm 2.50 \mathrm{~g}, 707$ $0.83 \pm 59.16 \mathrm{~g})(p=0)$.

As regards biochemical parameter during hospital stay (Table 2), we found that the number of newborn who suffered from hyperglycemia and cholestasis in group of Late lipid infusion was higher than those in group of Early lipid infusion ( $p=0.035$ and 0.001 respectively).

The parameter of the cortical auditory evoked potential are shown in Table 3.

\section{Discussion}

Developmental nutrition on preterm infants have documented the need for increased energy and protein intake started as early as possible after birth and demonstrated that the undernutrition which occurs in preterm is responsible for poor neurodevelopmental and neurocognitive outcomes [14] but it is not clear to what extent these physiological deficits might impair behavior [15]. It is well known and accepted that intravenous glucose or amino acids have to be given at a constant rate and in amounts that do not induce metabolic disturbances or exceed the metabolic capacity of the infant [14]. Intravenous lipid (IL) emulsions are important constituents of total parenteral nutrition (TPN) because they provide essential fatty acids and allow an increase in energy intake without giving an excess of glucose, which may be associated with an increase in carbon dioxide production [7]. However, the utilization of IL emulsions during the very first days of life was debated [16].That's why we tried to evaluate the effect of timing of introduction of intravenous lipid in the parenteral nutrition on the biochemical parameters of preterm and we recorded P1 as a biomarker of the auditory cortical evoked potential.

In the present work we found that group of early lipid infusion had reached their full oral intake earlier with shorter duration of parenteral nutrition and length of stay. They had better weight gain and significantly better glucose level control than group of late lipid infusion. There was no significant difference in the other chemical parameters between both groups expect for the higher incidence of cholestasis in the group of late lipid infusion. At 6 months of age, the group of early lipid infusion had significantly shorter latency and amplitude of P1 than the group of late lipid infusion. It is a consistent

Table 2 Biochemical parameters of the studied groups

\begin{tabular}{|c|c|c|c|c|c|c|}
\hline \multicolumn{2}{|c|}{ Laboratory parameter } & \multirow{2}{*}{$\begin{array}{l}\text { Early lipid infusion } \\
\text { No. }=26 \\
8(30.8 \%)\end{array}$} & \multirow{2}{*}{$\begin{array}{l}\text { Late lipid infusion } \\
\text { No. }=23 \\
14(60.9 \%)\end{array}$} & \multirow{2}{*}{$\begin{array}{l}\text { Test } \\
\text { value }\end{array}$} & \multirow[t]{2}{*}{$P$-value } & \multirow[t]{2}{*}{ Sig. } \\
\hline & Yes & & & & & \\
\hline \multirow[t]{2}{*}{ Urea } & Mean \pm SD & $5.69 \pm 0.62$ & $5.59 \pm 0.54$ & 0.581 & 0.564 & NS \\
\hline & Range & $5-7$ & $5-7$ & & & \\
\hline \multirow[t]{2}{*}{ Creatinine } & Mean \pm SD & $0.73 \pm 0.15$ & $0.74 \pm 0.14$ & $-0.211^{*}$ & 0.834 & NS \\
\hline & Range & $0.5-1.1$ & $0.6-1.1$ & & & \\
\hline \multirow[t]{2}{*}{ Sodium } & Mean \pm SD & $138.23 \pm 3.73$ & $138.43 \pm 3.88$ & $-0.187^{\circ}$ & 0.852 & NS \\
\hline & Range & $134-147$ & $134-147$ & & & \\
\hline \multirow[t]{2}{*}{ Potassium } & Mean \pm SD & $3.93 \pm 0.26$ & $3.92 \pm 0.26$ & $0.130^{*}$ & 0.897 & NS \\
\hline & Range & $3.5-4.6$ & $3.5-4.6$ & & & \\
\hline \multirow[t]{2}{*}{$\mathrm{Hco3}$} & Mean \pm SD & $22.19 \pm 1.60$ & $22.17 \pm 1.37$ & $0.043^{\circ}$ & 0.966 & NS \\
\hline & Range & $18-25$ & $19-25$ & & & \\
\hline \multirow[t]{2}{*}{ Albumin } & Mean \pm SD & $3.63 \pm 0.33$ & $3.53 \pm 0.63$ & $0.072^{\circ}$ & 0.44 & NS \\
\hline & Range & $3.5-4.9$ & $2.1-4.3$ & & & \\
\hline \multirow[t]{2}{*}{ Indirect bil } & Mean \pm SD & $6.92 \pm 1.79$ & $6.37 \pm 3.58$ & $-0.080^{\circ}$ & 0.13 & NS \\
\hline & Range & $3.5-9.5$ & $5.5-19.3$ & & & \\
\hline Cholestasis & Yes & $0(0.0 \%)$ & $8(34.8 \%)$ & $10.808^{*}$ & 0.001 & HS \\
\hline
\end{tabular}

*: Chi-square test

$\bullet:$ Independent $t$-test 
Table 3 The parameter of the cortical auditory evoked potential

\begin{tabular}{|c|c|c|c|c|c|c|}
\hline & & Early lipid infusion & Late lipid infusion & Test value & $P$-value & Sig. \\
\hline & & No. $=26$ & No. $=23$ & & & \\
\hline p1 latency (ms) & & & & & & \\
\hline at $500 \mathrm{HZ}$ & Mean \pm SD & $113.55 \pm 7.77$ & $184.09 \pm 24.01$ & -14.182 & 0.000 & HS \\
\hline & Range & $95.5-127.4$ & $149-234$ & & & \\
\hline at $2000 \mathrm{HZ}$ & Mean \pm SD & $114.56 \pm 7.62$ & $190.70 \pm 22.96$ & -15.960 & 0.000 & HS \\
\hline & Range & $97.2-130$ & $155-239$ & & & \\
\hline p1 latency left & & & & & & \\
\hline at $500 \mathrm{HZ}$ & Mean \pm SD & $113.29 \pm 7.60$ & $188.91 \pm 23.45$ & -15.564 & 0.000 & HS \\
\hline & Range & $96.1-128.1$ & $151-235$ & & & \\
\hline at $2000 \mathrm{HZ}$ & Mean \pm SD & $113.13 \pm 7.53$ & $193.43 \pm 21.38$ & -17.955 & 0.000 & HS \\
\hline & Range & $98-127$ & $156-239$ & & & \\
\hline p1 amplitude ri & & & & & & \\
\hline at $500 \mathrm{HZ}$ & Mean \pm SD & $3.31 \pm 0.73$ & $5.91 \pm 1.41$ & -8.216 & 0.000 & HS \\
\hline & Range & $2.09-4.8$ & $3.44-8.4$ & & & \\
\hline at $2000 \mathrm{HZ}$ & Mean \pm SD & $3.19 \pm 0.73$ & $9.23 \pm 1.42$ & -19.077 & 0.000 & HS \\
\hline & Range & $2.02-4.6$ & $6.6-11.8$ & & & \\
\hline p1 amplitude le & & & & & & \\
\hline at $500 \mathrm{HZ}$ & Mean \pm SD & $3.25 \pm 0.72$ & $5.85 \pm 1.41$ & -8.264 & 0.000 & HS \\
\hline & Range & $2.09-4.7$ & $3.4-8.3$ & & & \\
\hline at $2000 \mathrm{HZ}$ & Mean \pm SD & $3.31 \pm 0.69$ & $9.29 \pm 1.36$ & -19.712 & 0.000 & HS \\
\hline & Range & $2.22-4.5$ & $6.7-11.2$ & & & \\
\hline
\end{tabular}

$\because$ Independent t-test

observation among different studies that preterm infants have low fat depots and lack of essential fatty acids may affects brain development. Because of this, it has been recommended to administer amino acids and fat from the first day of life [17]. Postnatal growth restriction in preterm infants is mainly due to a low caloric intake during the first weeks of life therefore, recommendations have been changed, suggesting an early start with protein and fat supplementation [18]. Our results matched with valentine et al. who observed weight gain in 308 preterm VLBW infants who received early parenteral nutrition supplementation in comparison with 132 infants who did not receive early parenteral nutrition. It was also observed that infants in the early parental nutrition groups had a shorter duration of total parenteral nutrition administration and achieved full enteral feeds earlier [5]. Gnigler et al. showed that the duration of parenteral nutrition decreased after the introduction of the Computer Calculation Program for Individualized Parenteral Nutrition and has been associated with better growth and development of preterm infants [19]. Many studies proved that a possible explanation better weight gain in preterm allowed for an earlier stop of parenteral nutrition as the higher supply of amino acids and fat, allowed the administration of less total fluid by more concentrated solution. As less total fluid is administered when oral feedings are increased and the patient can be completely orally fed earlier. Other possibility is that babies with a better supply of amino acids and fat have tolerated the oral feedings better [20]. Our result of hyperglycemia in neonates with late lipid infusion may be explained by the fact that high cortisolconcentrations (endogenous or exogenous) also promote glucose production and protein catabolism in these infants. High glucagon concentrations in these infants contribute to glycogen breakdown and gluconeogenesis [21]. Matching to our results Ibrahim et al. showed statistically significant lower serum glucose levels in the early parenteral infusion group compared to the late parenteral infusion group, though both groups had serum glucose concentrations within normal ranges. They suggested that decrease in blood glucose might be due to the stimulatory effect of AA on insulin secretion [22]. Thureen and colleagues demonstrated higher insulin concentrations in infants receiving AA at $3 \mathrm{gm} /$ $\mathrm{kg} /$ day compared to those receiving $1 \mathrm{gm} / \mathrm{kg} /$ day [23] Murdock et al. showed that early introduction of AA and lipids lowers serum blood glucose levels [24]. As regards cholestasis in our patient it may be explained by the delay of enteral nutrition and longer duration of 
the parenteral nutrition in the group of late lipid infusion. The development of total parenteral nutrition (TPN) cholestasis might be the direct association of TPN and liver toxicity [25]. The absence or delay of physiological enteral intake may enhance liver damage. Earlier enteral feeding can reserve intestinal integrity, maintain intestinal hormones and enzymes secretion, prevent bacterial translocation, and interrupt the beginning of liver dysfunction that leads to cholestasis [26].

Evidence that malnutrition causes changes in auditory evoked potentialsmeasurements in children has been provided sparsely in the literature [27]. The P1 peak is robustly present and dominates the waveform morphology of the cortical auditory evoked potential in young children. It has been reported that over the first 2-3 years of life, there is a rapid decrease of the latency and the mean P1 latency in adults with normal hearing is approximately $60 \mathrm{~ms}$. [28] Similarly Gilley et al. [29] reported that the negative component following P1 (so called N1) is not consistently seen in normal hearing children until 12 years of age [29].

Latency of the P1 wave is thought to reflect the sum of synaptic transmission delays throughout the central auditory pathways .Latency changes in the P1, as a function of increasing age, reflect the maturation of the central auditory pathways occurring (at least in part) in response to auditory stimulation. This is most likely due to more efficient synaptic transmission over time [30]. Researchers have further described patterns of development that lead to changes in P1 latency and morphology [31].

Flinn et al. investigated potentials recorded in cortical areas, with the child's name as a stimulus. They observed that malnourished infants had a lower number of wave peaks and amplitudes than controls, after a nutritional recovery period of about four months [28]. Early initiation of n-3 and n- 6 fatty acids at 28-34 gestational weeks, than those treated at 34-37 weeks corrected pregnancy-induced essential fatty acids deficiency, maternal-fetal malnutrition and increased the fetal biparietal diameter [10].

Franz et al. showed that poor early neonatal $\mathrm{HC}$ growth was associated with abnormal neurological examination and abnormal mobility at the age of 5.4 years, and poor early neonatal weight gain was associated with abnormal neurological examination with lower mental processing composite scores in multiple regression models, accounting for perinatal risk factors and socioeconomic status [32]. Ehrenkranz et al. reported that, a higher rate of $\mathrm{HC}$ growth and weight gain from birth to discharge was associated with a lower incidence of cerebral palsy, subnormal mental developmental index, and neurodevelopmental impairment [33]. The cortically generated AEPs in normal hearing individuals continue to show maturational changes up to 15 years of age determined by latency and amplitude of the responses, and can therefore be used to assess cortical plasticity [31]. In our study, the latency of the P1 component of the cortical evoked response to sound infants who were delivered preterm varies as a result of early effective nutrition and, thus, can be used as a biomarker for maturation of central auditory pathways. As previously mentioned, the latency of the components of cortical potentials can be influenced by maturation. According to Hecox and Galambos [34], Wave I undergoes a process of maturation at about two or three months of life, and six months according to Isaac 1999 [35]. Odabas et al. [27] reported increased wave latencies (mainly for wave I) at all degrees of malnutrition. These findings suggest that malnutrition early in life may have a more marked effect on the caudal myelinationof the auditory pathway [27]. Similarly a study conducted with 15 newborns indicated that such increased latency values of the components $\mathrm{P} 1$ and $\mathrm{N} 1$ are justified by the immaturity of cortical structures in this population, regardless of gestational age [36].

In conclusion, the maturational differences in the auditory pathway between both groups highlighted by the P1 component may reflect the effect of early effective nutrition on higher centers brain development.

\section{Author details \\ ${ }^{1}$ Pediatrics Department, Faculty of Medicine, Ain Shams University, Cairo, Egypt. ${ }^{2}$ Audiology Department, Unit ENT Departments, Faculty of Medicine, Ain Shams University, 4, hashem al Ashkar Street, el nozha el gedida, Cairo 11843, Egypt.}

Received: 4 May 2018 Accepted: 24 November 2018 Published online: 11 November 2019

\section{References}

1. Wang L, Xu RJ (2007) The effects of perinatal protein malnutrition on spatial learning and memory behavior and brain-derived neurotrophic factor concentration in the brain tissue in young rats. Asia Pacific J Clin Nutrit 16:467-472 2. Ehrenkranz RA, Dusick AM, Vohr BR, Wright LL, Wrage LA, Poole WK (2006) Growth in the neonatal intensive care unit influences neurodevelopmental and growth outcomes of extremely low birth weight infants. Pediatrics. 117: 1253-1261

3. Ehringer W, Belcher D, Wassall SR, Stillwell W (1990) A comparison of the effects of linoleic (18:3w3) and docosahexaenoic (22:6w3) acids on phospholipid bilayers. Chem Phys Lipids 54:79-88

4. Franz AR, Pohlandt F, Bode $\mathrm{H}$ et al (2009) Postdischarge growth and neurodevelopmental outcome at 5.4 years in extremely preterm infants after intensive neonatal nutritional support. Pediatrics. 123:e101-e109

5. Valentine CJ, Fernandez S, Rogers LK et al (2009) Early amino-acid administration improves preterm infant weight. J Perinatol 29:428-432

6. Uauy R, Tsang R, Koletzko B, Zlotkin S (2005) Concepts, definitions and approaches to define the nutritional needs of LBW infants. In: Tsang R, Uauy R, Koletzko B, Zlotkin S (eds) Nutrition of the Preterm Infant: Scientific Basis and Practical Guidelines, 2nd edn. Digital Education Publishing, Cincinnati, pp 1-21

7. Douglas D, Connie M, Shirley G, Matt N, Kamlesh S (2008) Randomized trial of very low birth weight infants receiving higher rates of infusion of intravenous fat emulsions during the first week of life. Pediatrics. 122:743-751

8. Fishman MA, Prensky AL, Dodge PR (1969) Low content of cerebral lipids in infants suffering from malnutrition. Nature. 221:552-553

9. Nelson GK, Dean RF (1959) The electroencephalogram in African children: effects of kwashiorkor and a note on the newborn. Bull World Health Organ 21:779-782

10. Flinn JM, Barnet AB, Lydick S, Lackner J (1993) Infant malnutrition affects cortical auditory evoked potentials. Percept Mot Skills 76:1359-1362

11. Mochizuki Y, Tohshin G, Ohkibo H, Tatara T, Motomura T (1982) Developmental changes of brainstem auditory evoked potentials in 
normal human subjects from infants to young adults. Brain and Development 4:127-136

12. De Lima GJ, Funayama CA, De Oliveira LM, Rossato M, Colafemina JF (2008) Effects of malnutrition and sensory-motor stimulation on auditory evoked potentials. Psychol Neurosci 1:121-127 https://doi.org/10.3922/j.psns.2008.2.005

13. Wunderlich J, Cone-Wesson B, Shepherd R (2006) Maturation of the cortical auditory evoked potential in infants and young children. Hear Res 212:185-202

14. Hay WW (2013) Aggressive nutrition of the preterm infant. Curr Pediat Rep 1(4). https://doi.org/10.1007/s40124-013-0026-4 https://doi.org/10.1007/ s40124-013-0026-4

15. Bellisle F (2004) Effects of diet on behavior and cognition in children. Br J Nutr 92:S227-\$232

16. Salama GS, Kaabneh MA, Almasaeed MN, Alquran MI (2015) Intravenous lipids for preterm infants: a review. Clinical medicine insights. Pediatrics. 9 25-36 https://doi.org/10.4137/CMPed.S21161

17. Thureen PJ (1999) Early aggressive nutrition in the neonate. Pediatr Rev 20:45-e55

18. Garcia LV, Erroz IO, Freire MM et al (2012) Does early parenteral protein intake improve extrauterine growth in low birth weight preterms? An Pediatr (Barc) 76:127-132

19. Gnigler M, Schlenz B, Kiechl-Kohlendorfer U, Rudiger M (2014) Improved weight gain in very-low-birth-weight infants after the introduction of a self-created computer calculation program for individualized parenteral nutrition. Pediatr Neonatol 55:41-47 https://doi.org/10.1016/j.pedneo.2013.05.010

20. Stephens BE, Walden RV, Gargus RA et al (2009) First-week protein and energy intakes are associated with 18-month developmental outcomes in extremely low birth weight infants. Pediatrics. 23:1337-1343

21. Van der Lugt NM, Smits-Wintjens VEHJ, van Zweiten PHT (2010) Short and long term outcome of neonatal hyperglycaemia in very preterm infants: a retrospective follow-up study. BMC Pediatr 10:52-58

22. Ibrahim HM, Jeroudi MA, Baier RJ et al (2004) Aggressive early total parental nutrition in low-birth-weight infants. J Perinatol 24:482-486

23. Thureen PJ, Melara D, Fennessey PV, Hay WW (2003) Effect of low versus high intravenous amino acid intake on very low birth weight infants in the early neonatal period. Pediatr Res 53:24-32

24. Murdock N, Crighton A, Nelson LM, Forsyth JS (1995) Low birthweight infants and total parenteral nutrition immediately after birth. II. Randomized study of biochemical tolerance of intravenous glucose, amino acids, and lipid. Arch Dis Child Fetal Neonatal Ed 73:F8-12

25. Alkharfy TM, Ba-Abbad R, Hadi A, Sobaih BH, AlFaleh KM (2014) Total parenteral nutrition- associated cholestasis and risk factors in preterm infants. Saudi J Gastroenterol Off J Saudi Gastroenterol Assoc 20:293-296 https://doi.org/10.4103/1319-3767.141688

26. Guglielmi FW, Boggio-Bertinet D, Federico A et al (2006) Total parenteral nutrition-related gastroenterological complications. Dig Liver Dis 38:623-642

27. Odabas D, Caksen H, Sar S et al (2005) Auditory brainstem potentials in children with protein energy malnutrition. Int J Pediatr Otorhinolaryngol 69:923-928

28. Jang JH, Jang HK, Kim SE, Oh SH, Chang SO, Lee JH (2010) Analysis of P1 latency in normal hearing and profound sensorineural hearing loss. Clin Exp Otorhinolaryngol 3:194-198 https://doi.org/10.3342/ceo.2010.3.4.194

29. Gilley P, Sharma A, Dorman M, Martin K (2006) Abnormalities in central auditory maturation in children with language-based learning problems. Clin Neurophysiol 117:49-56

30. Purdy SC, Gardner-Berry K (2009) Auditory evoked potentials and Cochlear implants: research findings and clinical applications in children, perspectives on hearing \& hearing disorders in childhood. J Am Speech Hear Assoc 19:14-21

31. Dorman MF, Sharma A, Gilley P, Martin K, Ronald P (2007) Central auditory development: evidence from CAEP measurements in children fit with cochlear implants. J Commun Disord 40:284-294 https://doi.org/10.1016/j.jcomdis.2007.03.007

32. Salama GS, Haabneh MA, Almasaeed MN (2015) Intravenous lipid for preterm infants: a review. Clinical medicine insights. Pediatrics. 9:25-36 https://doi.org/10.4137/CMPed.S21161

33. Franz AR, Pohlandt F, Intrauterine Bode $\mathrm{H}$ et al (2009) Neonatal, and post discharge growth and neurodevelopmental outcome at 5.4 years in extremely preterm infants after intensive neonatal nutritional support. Pediatrics. 123:e101-e109

34. Hecox K, Galambos R (1974) Brainstem auditory responses in human infants and adults. Arch Otolaryngol 99:30-33

35. Isaac ML (1999) Estudo da maturacao das vias auditivas por meio dos potenciais auditivos evocados de tronco cerebral em criancas pre-termo e a termo ate 18 meses de idade. Unpublished Doctoral Thesis. Universidade de Sao Paulo

36. Salamy A, Mckean CM (1976) Postnatal development of human brainstem potentials during the first year of life. Electroencephalogr Clin Neurophysiol 40:418-426

\section{Publisher's Note}

Springer Nature remains neutral with regard to jurisdictional claims in published maps and institutional affiliations.

\section{Submit your manuscript to a SpringerOpen ${ }^{\circ}$ journal and benefit from:}

- Convenient online submission

- Rigorous peer review

- Open access: articles freely available online

High visibility within the field

- Retaining the copyright to your article

Submit your next manuscript at $>$ springeropen.com 